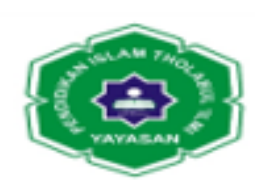

Jurnal Ilmiah METADATA

\title{
PENGARUH MOTIVASI DAN PENGALAMAN KERJA TERHADAP PRODUKTIVITAS KERJA KARYAWAN PADA PT. TRIKARYA CEMERLANG MEDAN
}

\author{
Sarman Sinaga \\ Pascasarjana Magister Manajemen Universitas Darma Agung \\ email : sarmansinaga17@gmail.com
}

\begin{abstract}
ABSTRAK
Penelitian ini bertujuan untuk menguji pengaruh variabel motivasi dan pengalaman kerja terhadap produktivitas kerja karyawan pada PT.Trikarya Cemerlang Medan. Data yang digunakan dalam penelitian ini adalah data primer yang diperoleh melalui kuesioner. Populasi dalam penelitian ini adalah seluruh karyawan pada PT.Trikarya Cemerlang Medan sebanyak \pm 700 , sedangkan sampelnya terdiri dari 50 karyawan PT.Trikarya Cemerlang Medan yang bekerja di Transmart Medan Fair. Metode pengambilan sampel mengunakan simple random sampling. Variabel dependen dalam penelitian ini yaitu produktivitas kerja, serta variabel independennya yaitu motivasi dan pengalaman kerja. Metode analisis data mengunakan analisis linear berganda. Sehingga berdasarkan hasil penelitian diperoleh persamaan regresi linier berganda yaitu $Y=2,295+0,403(X 1)+0,582(X 2)$. Selain itu hasil penelitian menunjukkan bahwa nila $F$ hitung sebesar 71,132 lebih besar dari nilai $\mathrm{F}$ tabel 3.20, serta tingkat signifikannya lebih kecil dari 0,005 yaitu $0,000(0,000<0,05)$ sehingga dapat disimpulkan motivasi dan pengalaman kerja secara bersama-sama atau simultan berpengaruh terhadap produktivitas kerja karyawan. Secara parsial hasil penelitian menunjukkan bahwa nilai signifikan motivasi adalah $0,000<0,05$. Serta nilai $t_{\text {hitung }}$ yang lebih besar dari $t_{\text {tabel }}$ yaitu 4,404 > 2.01174 sehingga dapat disimpulkan motivasi berpengaruh signifikan terhadap produktivitas kerja karyawan. Sedangkan, pengalaman kerja secara parsial berpengaruh signifikan terhadap produktivitas kerja karyawan sesuai dengan nilai signifikan $0,000<0,05$. Serta nilai $t_{\text {hitung }}$ yang lebih besar dari $t_{\text {tabel }}$ yaitu 3,902 $>$ 2.01174. Berdasarkan nilai Adjusted $R$ Square diperoleh nilai 0,741. Yang artinya besar pengaruh variabel independen yaitu motivasi dan pengalaman kerja terhadap perubahan variabel dependen berupa produktivitas kerja karyawan sebesar 74,1\%, sedangkan $25,9 \%$ dipengaruhi oleh variabel lain di luar penelitian.
\end{abstract}

Kata Kunci : Motivasi, Pengalaman Kerja, Produktivitas Kerja Karyawan

\section{THE EFFECT OF MOTIVATION AND WORK EXPERIENCE ON EMPLOYEE WORK PRODUCTIVITY AT PT. TRIKARYA CEMERLANG MEDAN}

\section{ABSTRACT}

This research aims to examine the effect of motivation and work experience variables on employee work productivity at PT.Trikarya Cemerlang Medan. The data used in this study are primary data obtained through questionnaires. The population in this study were all employees at PT.Trikarya Cemerlang Medan as 


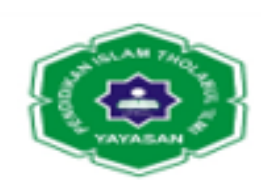

\section{Jurnal Ilmiah METADATA}

much as \pm 700 , while the sample consisted of 50 employees of PT.Trikarya Cemerlang Medan who worked at Transmart Medan Fair. The sampling method uses simple random sampling. The dependent variable in this study is work productivity, and the independent variables are motivation and work experience. The data analysis method uses multiple linear analysis. So based on the results of the study obtained by the multiple linear regression equation is $\quad \mathrm{Y}=2.295+$ 0.403 (X1) +0.582 (X2). Besides the results of research showed that the calculated $F$ value of 71.132 was greater than the $F$ value of table 3.20, and the significance level was less than 0.005 , namely $0.000(0.000<0.05)$ so that it could be concluded that motivation and work experience together or simultaneously had an effect on work productivity the employee. Partially the results of the study showed that the significant value of motivation was $0,000<0.05$. And the value of tcount is greater than ttable that is 4,404>2,01174 so that it can be concluded that motivation has a significant effect on employee productivity. Meanwhile, work experience partially has a significant effect on employee work productivity in accordance with a significant value of $0,000<0.05$. And the value of t_count which is greater than t_table is 3.902> 2.01174. Based on the Adjusted R Square value, the value is 0.741 . Which means that the influence of the independent variable is the motivation and work experience on the change in the dependent variable in the form of employee productivity of $74.1 \%$, while $25.9 \%$ is influenced by other variables outside the study.

Keyword : Motivation, Work Experience, Employee Work Productivity

\section{PENDAHULUAN}

Produktifitas kerja adalah kemampuan karyawan dalam berproduksi dibandingkan dengan input yang digunakan. Seorang karyawan dikatakan produktif jika mampu menghasilkan barang dan jasa sesuai dengan yang diharapkan dalam waktu yang singkat dan tepat. Produktifitas bagi karyawan merupakan persyaratan kerja yang harus dipenuhi oleh setiap karyawan. Ada dua faktor penting yang mendukung tercapainya tingkat produktifitas yaitu motivasi dan pengalaman kerja karyawan. Berdasarkan uraian diatas penulis mencoba untuk melakukan penelitian pada PT. Trikarya Cemerlang Medan dengan judul penelitian "Pengaruh Motivasi dan Pengalaman Kerja terhadap Produktivitas Kerja Karyawan pada PT.Trikarya Cemerlang Medan".

Produktifitas kerja setia orang berbeda berdasarkan pengalaman, umur dan tingkat Pendidikan seorang pegawai/karyawan. Karyawan/pegawai yang berprestasi adalah seorang yang bekerja disiplin terhadap waktu dan rapi dan rajin terhadap laporan pekerjaan. Pegawai/karyawan harus mengikuti arahan pimpinan dan tidak menyalahgunakan kepercayaan pimpinan, rekan sejawat dan bawahan (Karim, A. 2019); Sitompul S. 2019); Nasution, L. 2019); (Ichsan, R. 2020). 


\section{당 \\ Jurnal Ilmiah METADATA}

\section{METODE PENELITIAN}

\section{Lokasi dan Waktu Penelitian}

Penelitian dilakukan di PT.Trikarya Cemerlang Medan yang berlokasi di Jl. Gatot Subroto No.30 Medan Petisah, Kota Medan, Sumatera Utara. Penelitian dilaksanakan dari bulan April 2019 sampai Agustus 2019.

\section{Populasi dan Sampel}

\section{Populasi}

Menurut Sugiyono (2015:148), "Populasi adalah wilayah generalisasi yang terdiri atas objek atau subjek yang mempunyai kuantitas dan karakteristik tertentu yang ditetapkan oleh penelitian untuk dipelajari dan kemudian ditarik kesimpulannya". Populasi dalam penelitian ini adalah seluruh karyawan pada PT. Trikarya Cemerlang Medan sebanyak \pm 700 .

\section{Sampel}

Menurut Sugiyono (2015:149), "Sampel adalah bagian dari jumlah dan karakteristik yang dimiliki oleh populasi dan harus bersifat representatif (mewakili)"

Teknik Pengambilan Sampel Acak Sederhana adalah pengambilan sampel dari anggota populasi yang dilakukan secara acak tanpa memperhatikan strata yang ada dalam populasi tersebut. Berdasarkan teknik ini maka sampel dalam penelitian berjumlah 50 karyawan PT.Trikarya Cemerlang yang bekerja di Transmart-Medan Fair.

\section{Defenisi Operasional dan Pengukuran Variabel}

1. Variabel Terikat (Dependent Variabel)

Variabel dependent dalam penelitian ini adalah Produktivitas Kerja Karyawan 2. Variabel Bebas (Independent Variabel)

Variabel Independent penelitian ini ada dua yaitu Motivasi dan Pengalaman Kerja.

\section{Jenis dan Sumber Data}

Jenis data yang digunakan dalam penelitian ini adalah data kuantitatif. Data kuantitatif menurut Sugiyono (2015:35) adalah data yang berbentuk angka atau data kualitatif yang diangkakan. Sumber data dalam penelitian ini adalah data primer dan sekunder. Data primer adalah data yang diperoleh peneliti secara langsung dari hasil observasi. Sedangkan data sekunder adalah data yang diperoleh peneliti dari sumber yang sudah ada atau tidak secara langsung.

\section{Metode Pengumpulan Data}

1. Observasi

Metode pengumpulan data yang digunakan adalah :

2. Wawancara

3. Studi Kepustakaan

4. Kusioner

\section{Uji Validitas dan Realibilitas}

Uji validitas dan realibilitas ini bertujuan untuk menguji apakah kuesioner yang disebarkan untuk mend apatkan data penelitian adalah valid dan reliabel.

\section{Uji Validitas}

Validitas adalah sejauh mana suatu alat ukur itu menunjukan ketepatan dan kesesuaiaan. Menurut Sugiyono (2012:348), validitas menunjukan derajat 


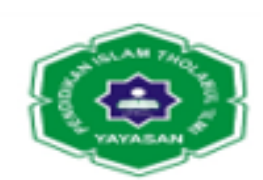

\section{Jurnal Ilmiah METADATA}

ketepatan antara data yang sesungguhnya terjadi pad a objek dengan data yang dapat dikumpulkan oleh peneliti. Uji validitas digunakan untuk mengetahui apakah setiap butir dalam instrument itu valid atau tidak. Degan dasar penilaian $r$ hitung $>r$ tabel, maka instrumen atau item pertanyaan berkolerasi signifikan terhadap skor total (valid).

\section{Uji Reliabilitas}

Menurut Sugiyono (2013:173), "Reliabilitas adalah sejauh mana hasil pengukuran dengan menggunakan objek yang sama akan menghasilkan data yang sama". Dengan dasar pengambilan keputusan yaitu Jika Alpha $>0,600$, maka instrumen tersebut dikatakan reliabel.

\section{Uji Asumsi Klasik}

Ghozali (2016:105) menyatakan bahwa analisis regresi linear berganda perlu menghindari penyimpangan asumsi klasik supaya tidak timbul masalah dalam penggunaan analisis tersebut dan untuk mengetahui apakah model regresi yang digunakan dalam penelitian adalah model yang baik serta tidak bias. Pengukuran asumsi klasik dalam penelitian ini meliputi :

\section{Uji Normalitas}

Uji normalitas data dapat dilakukan dengan menggunakan metode grafik histogram, P-P Plot of Regresion Standardizerd Residual dan Uji One Sample Kolmogorov-Smirnov.

2. Uji Multikolinearitas

Uji multikolinearitas adalah pengujian yang mempunyai tujuan untuk menguji apakah dalam model regresi ditemukan adanya korelasi antara variabel independen (Ghozali,2016:103).

3. Uji Heteroskedastisitas

Uji Heteroskedastisitas bertujuan untuk menguji apakah dalam model regresi terjadi ketidaksamaan variance dari residual satu pengamatan ke pengamatan yang lain (Ghozali,2016:134).

\section{Metode Analisis Data dan Uji Hipotesis \\ Metode Analisis Data \\ Uji Statistik Deskriptif}

Uji Statistik deskriptif digunakan untuk menilai variabel $\mathrm{X}$ dan variabel $\mathrm{Y}$, maka analisis yang digunakan yaitu nilai minimum, nilai maksimum, mean (ratarata), dan standar deviasi dari setiap variabel. Analisis Regresi Liniear Berganda

Analisis ini digunakan untuk mengetahui arah hubungan antara variabel independen dengan variabel dependen. Persamaan regresi linear berganda penelitian ini dapat dirumuskan sebagai berikut:

\section{Pengujian Hipotesis \\ Pengujian Hipotesis Secara Parsial (Uji t)}

Kriteria pengambilan keputusan adalah sebagai berikut :

1. Ho diterima jika thitung $<$ ttabel pada $\alpha=5 \%$ atau jika $p$-value $>0,05$

2. Ha diterima jika thitung $>$ ttabel pada $\alpha=5 \%$ atau jika $p$-value $<0,05$.

Pengujian Hipotesis Secara Simultan (Uji F)

Kriteria pengambilan keputusan sebagai berikut :

1. Ho diterima jika Fhitung $<$ Ftabel pada $\alpha=5 \%$ atau jika $p$-value $>0,05$. 


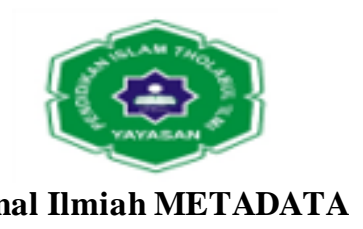

2. Ha diterima jika Fhitung $>$ Ftabel pada $\alpha=5 \%$ atau jika $p$-value $<0,05$.

\section{Koefisien Determinasi}

Koefesien determinasi $\left(\mathrm{R}^{2}\right)$ merupakan sebuah ukuran untuk menilai seberapa jauh kemampuan model variabel independen dalam menerangkan variasi nilai dependen. Nilai $\mathrm{R}^{2}$ yang kecil berarti kemampuan variabel independen dalam menjelaskan variasi variabel dependen amat terbatas. Sedangkan, nilai yang mendekati satu berarti variabel independen memberikan hampir semua informasi yang dibutuhkan untuk memprediksi variasi dependen (Ghozali,2016:98).

\section{HASIL DAN PEMBAHASAN Gambaran Umum Perusahaan}

PT. Trikarya Cemerlang adalah sebuah perusaaan yang bergerak di bidang jasa cleaning service dan beroperasional mulai pukul 06.00 WIB - pukul 22.00 WIB. Perusahaan memiliki layanan berkualitas dengan hasil layanan bisnis pembersih, yang mampu membuat tempat kerja yang bersih dan sehat untuk mitra bisnisnya.

1. Visi Perusahaan

Memberi solusi dan Memfasilitas

2. Misi Perusahaan

Kami dipercaya oleh para pebisnis dan pemimpin industri untuk pembersihan komersial. Layanan kebersihan dan kepuasan pelanggan merupakan control kualitas keunggulan perusahaan dan sistem pembersihan akan memastikan pemberian kualitas yang baik.

PT. Trikarya Cemerlang memiliki organisasi yang terstruktur. Struktur organisasi adalah sebuah susunan berbagai komponen atau unit-unit kerja dalam sebuah organisasi yang ada di masyarakat. Struktur organisasi bertujuan untuk pembagian kerja yang teratur.

\section{Analisis Statistik Deskriptif}

Karakteristik Responden sebagai berikut :

TABEL 4.1

Statistik Deskriptif Jenis Kelamin

\begin{tabular}{|r|c|c|}
\hline $\begin{array}{r}\text { Jenis } \\
\text { Kelamin }\end{array}$ & $\begin{array}{r}\text { Jumlah } \\
\text { (orang) }\end{array}$ & $\begin{array}{r}\text { Persentase } \\
(\boldsymbol{\%})\end{array}$ \\
\hline Laki-laki & 20 & 40 \\
\hline Perempuan & 30 & 60 \\
\hline Jumlah & $\mathbf{5 0}$ & $\mathbf{1 0 0}$ \\
\hline
\end{tabular}

Sumber : Diolah Oleh Penulis 2019

TABEL 4.2

Statistik Deskriptif Usia Responden

\begin{tabular}{|c|c|c|}
\hline $\begin{array}{c}\text { Usia } \\
\text { (tahun) }\end{array}$ & $\begin{array}{c}\text { Jumlah } \\
\text { (orang) }\end{array}$ & $\begin{array}{c}\text { Persentase } \\
(\%)\end{array}$ \\
\hline $19-22$ & 21 & 42 \\
\hline $23-26$ & 27 & 54 \\
\hline $27-30$ & 2 & 4 \\
\hline
\end{tabular}




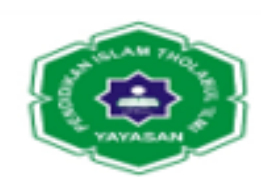

Jurnal Ilmiah METADATA

\begin{tabular}{|c|c|c|}
\hline Jumlah & $\mathbf{5 0}$ & $\mathbf{1 0 0}$ \\
\hline \multicolumn{3}{|c|}{ Sumber : Diolah Oleh Penulis 2019}
\end{tabular}

TABEL 4.3

Statistik Deskriptif Tingkat Pendidikan Responden

\begin{tabular}{|c|c|c|}
\hline $\begin{array}{c}\text { Tingka } \\
\text { Pendidikan }\end{array}$ & $\begin{array}{c}\text { Jumlah } \\
\text { (orang) }\end{array}$ & $\begin{array}{c}\text { Persentase } \\
(\mathbf{\%})\end{array}$ \\
\hline SMA & 13 & 26 \\
\hline DIPLOMA & 17 & 34 \\
\hline SARJANA & 20 & 40 \\
\hline Total & $\mathbf{5 0}$ & $\mathbf{1 0 0}$ \\
\hline
\end{tabular}

Sumber : Diolah Oleh Penulis 2019

TABEL 4.4

Statistik Deskriptif Masa Kerja Responden

\begin{tabular}{|c|c|c|}
\hline $\begin{array}{c}\text { Lama } \\
\text { Bekerja } \\
\text { (tahun) }\end{array}$ & $\begin{array}{c}\text { Jumlah } \\
\text { (orang) }\end{array}$ & $\begin{array}{c}\text { Persentase } \\
(\boldsymbol{\%})\end{array}$ \\
\hline $0-3$ & 41 & 82 \\
\hline $4-6$ & 9 & 18 \\
\hline Total & $\mathbf{5 0}$ & $\mathbf{1 0 0}$ \\
\hline
\end{tabular}

Sumber : Diolah Oleh Penulis 2019

\section{Uji Validasi dan Realibitas}

\section{Uji Validasi}

Dari hasil uji diketahui bahwa masing-masing butir pernyataan pada variable Motivasi Kerja (X1), Pengalaman Kerja (X2) dan produktivitas Kerja (Y) memiliki nilai Corrected Item-Total Correlation yang lebih besar dari $\mathrm{r}$ tabel $(0,28787)$, maka setiap pernyataan tersebut dinyatakan valid.

\section{Uji Realibitas}

TABEL 4.6

Hasil Uji Realibitas Pertanyaan

Reliability Statistics

\begin{tabular}{|c|c|l|}
\hline Variabel & Alpha & Status \\
\hline MOtivasi & 0,921 & Reliable \\
\hline Pengalaman Kerja & 0,908 & Reliable \\
\hline Produktivitas Kerja & 0,917 & Reliable \\
\hline
\end{tabular}

Sumber : Dari data yang diperoleh dilapangan (2019).

\section{Uji Asumsi Klasik}

\section{Uji Normalitas}

Uji ini digunakan untuk menguji apakah dalam sebuah model regresi, variabel dependen, variabel independen, mempunyai distribusi normal atau tidak. Penelitian ini mengunakan pengujian metode histogram, P-P Plot of Regresion Standardizerd Residual dan Uji One Sample Kolmogorov-Smirnov.

Gambar 4.2

$$
\text { Grafik Histogram }
$$




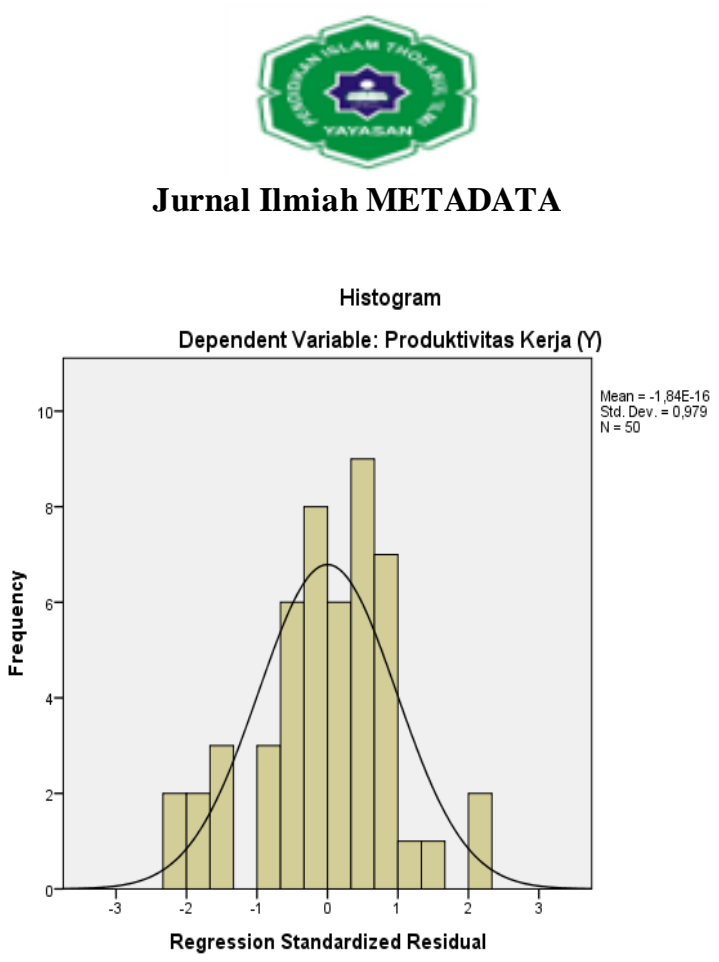

Sumber : Hasil Pengolahan Data dengan SPSS (2019).

Gambar 4.3

Uji Normalitas P-P Plot of Regession Standardize Residul

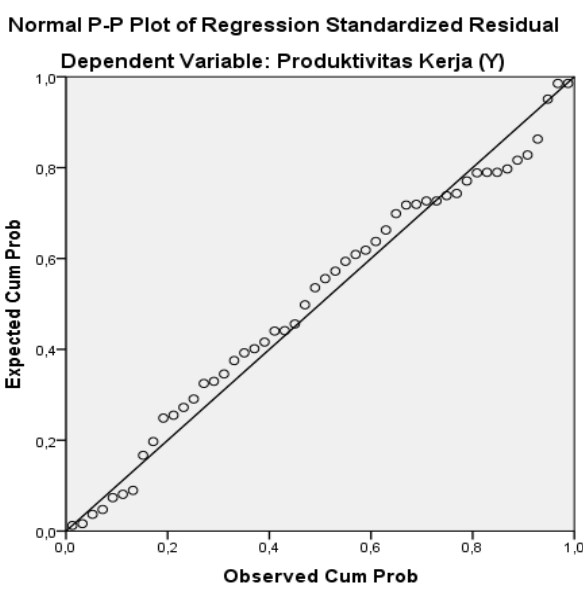

Sumber : Hasil Pengolahan Data dengan SPSS (2019).

Tabel 4.7

Uji Normalitas One Sample kolmogrov-smirnov

iple Kolmogorov-Smirnov Test

\begin{tabular}{|ll|r|}
\hline & & $\begin{array}{r}\text { tand ardized } \\
\text { Residual }\end{array}$ \\
\hline $\mathrm{N}$ & & 50 \\
Normal & &, 0000000 \\
Parameters ${ }^{\mathrm{a}, \mathrm{b}}$ &. & \\
& $\mathrm{D}$ & \\
& ev & 3,44834634 \\
& iat & \\
& io & \\
& n & \\
& te &, 087
\end{tabular}




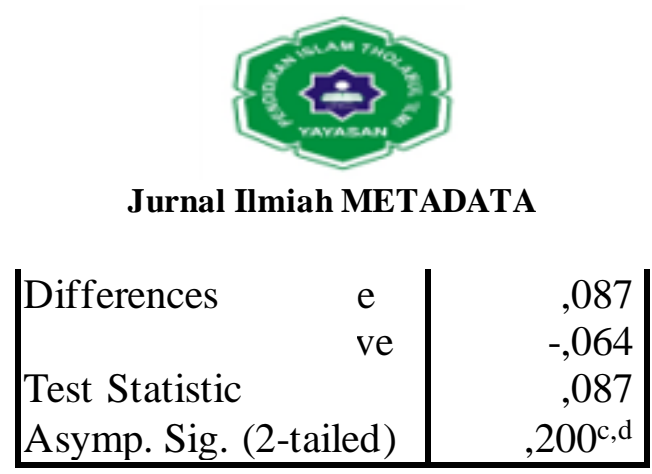

Sumber : Hasil Pengolahan Data dengan SPSS (2019).

2. Uji Multikolonearitas

Tabel 4.8

Uji Multikolinearitas

\begin{tabular}{|l|c|c|}
\hline \multirow{2}{*}{ Model } & \multicolumn{2}{|c|}{$\begin{array}{c}\text { Collinearity } \\
\text { Statistics }\end{array}$} \\
\cline { 2 - 3 } & $\begin{array}{c}\text { Toleranc } \\
\mathrm{e}\end{array}$ & VIF \\
\hline (Constant) & & \\
Motivasi &, 426 & 2,345 \\
(X1) &, 426 & 2,345 \\
Pengalaman & & \\
Kerja (X2) & & \\
\hline
\end{tabular}

Sumber : Hasil Pengolahan Data Dengan SPSS (2019).

Sehingga dapat disimpulkan tidak terjadi gejala multikoleneartitas pada valiabel independen yaitu motivasi dan pengalaman kerja.

\section{Uji Heterokedasitas}

Gambar 4.4

Uji Heterosked astisitas

Scatterplot

Dependent Variable: Produktivitas Kerja $(M$

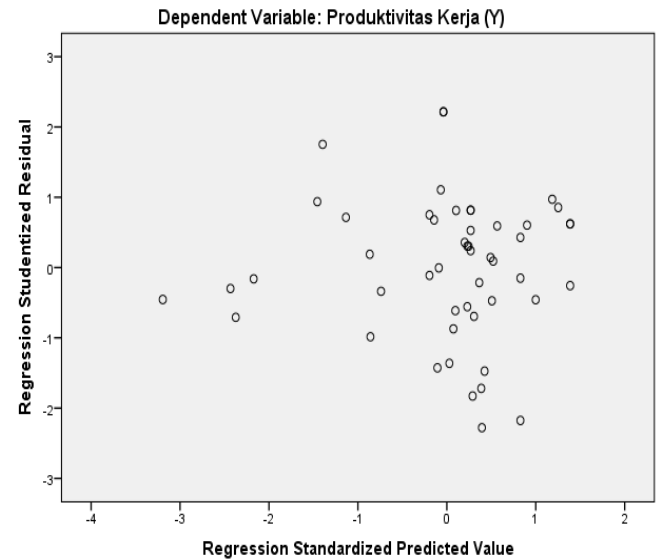

Sumber : Hasil Pengolahan Data Dengan SPSS (2019).

\section{Analisis Linear Berganda}

Persamaan regresi linear berganda, seperti di bawah ini:

$$
\mathrm{Y}=\mathbf{2 , 2 9 5}+\mathbf{0 , 4 0 3} \mathrm{X} 1+\mathbf{0 , 5 8 2} \mathrm{X2}
$$

Dari persamaan ini dapat diketahui bahwa produktivitas kerja sebesar 2,295 yang artinya jika nilai dari variabel motivasi dan pengalaman kerja kostan, maka besarmya nilai produktivitas kerja adalah 2,295

\section{Pengujian Hipotesis \\ Pengujian Hipotesis Secara Parsial (Uji t)}

Tabel 4.10 
Jurnal Ilmiah METADATA

Hasil Uji Signifikansi Parsial

\begin{tabular}{|l|r|r|}
\hline & & \\
Model & $\mathrm{t}$ & Sig. \\
\hline (Constant) &, 960 &, 342 \\
Motivasi (X1) & 4,404 &, 000 \\
Pengalaman Kerja & 3,902 &, 000 \\
(X2)
\end{tabular}

Sumber : Hasil Pengolahan Data Dengan SPSS (2019).

\section{Pengujian Hipotesis Secara Simultan (Uji F)}

Tabel 4.11

Hasil Uji Signifikansi Simultan

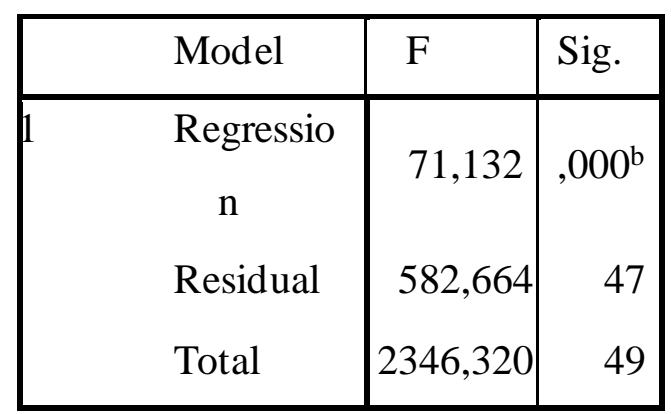

Sumber : Hasil Pengolahan Data Dengan SPSS (2019).

\section{Koefesien Determinasi}

Tabel 4.12

Koefesien Determinasi

\begin{tabular}{|c|c|c|c|c|}
\hline \multicolumn{5}{|c|}{ Model Summary ${ }^{b}$} \\
\hline $\begin{array}{l}\text { Mode } \\
1\end{array}$ & $\mathrm{R}$ & $\begin{array}{l}\mathrm{R} \\
\text { Square } \\
\end{array}$ & $\begin{array}{l}\text { Adjuste } \\
\text { d } \\
\text { R } \\
\text { Square } \\
\end{array}$ & $\begin{array}{r}\text { Std. } \\
\text { Error } \\
\text { of the } \\
\text { Estimat } \\
\mathrm{e} \\
\end{array}$ \\
\hline 1 & $867^{\mathrm{a}}$ & ,752 & ,741 & 3,52095 \\
\hline
\end{tabular}

Sumber : Hasil Pengolahan Data Dengan SPSS (2019).

\section{Pembahasan Hasil Penelitian}

Pengaruh Motivasi Kerja terhadap Produktivitas Kerja Karyawan

Hasil penelitian ini menunjukkan bahwa tingginya motivasi yang diterima karyawan dapat meningkatkan produktivitas kerja karyawan PT.Trikarya Cemerlang Medan.

Pengaruh Pengalaman Kerja terhadap Produktivitas Kerja Karyawan

Hasil penelitian ini menunjukkan bahwa karyawan yang berpengalaman kerja memiliki tingkat produktivitas kerja yang optimal. Pada dasarnya pengalaman 


\section{당 \\ Jurnal Ilmiah METADATA}

kerja memiliki pengaruh yang besar terhadap peningkatan produktivitas kerja karyawan karena pengalaman kerja akan menambah keterampilan kerja karyawan. Pengaruh Motivasi dan Pengalaman Kerja terhadap Produktivitas Kerja Karyawan

Persamaan regresi linier berganda penelitian ini yaitu $\mathrm{Y}=2,295+0,403(\mathrm{X} 1)+0,582(\mathrm{X} 2)$, hal ini menunjukkan bahwa nilai kostanta dari produktivitas kerja yaitu sebesar 2,295. Jika diasumsikan motivasi dan pengalaman kerja perusahaan kostan. Maka produktivitas kerja akan naik. Bila terjadi peningkatan independent.

\section{KESIMPULAN}

Berdasarkan Hasil penelitian mengenai "Analisis Pengaruh Motivasi dan Pengalaman Kerja terhad ap Produktivitas Kerja Karyawan PT.Trikarya Cemerlang Medan, maka dapat ditarik kesimpulan sebagai berikut :

1.Motivasi secara parsial berpengaruh signifikan terhadap produktivitas kerja pada PT.Trikarya Cemerlang Medan. Dari hasil penelitian diperoleh nilai koefesien regresi motivasi adalah 0,490 dengan nilai signifikan $0,000<0,05$. Serta nilai $t_{\text {hitung }}$ yang lebih besar dari $t_{\text {tabel }}$ yaitu 4,404 > 2.01174 .

2.Pengalaman Kerja secara parsial berpengaruh signifikan terhadap produktivitas kerja pada PT.Trikarya Cemerlang Medan. Dari hasil penelitian diperoleh nilai koefesien regresi pengalaman kerja adalah 0,434 dengan nilai signifikan $0,000<$ 0,05 . Serta nilai $t_{\text {hitung }}$ yang lebih besar dari $t_{\text {tabel }}$ yaitu3,902> 2.01174 .

3.Produktivitas karyawan PT.Trikarya Cemerlang Medan dipengaruhi oleh motivasi dan pengalaman kerja sebesar $74,1 \%$, sedangkan $25,9 \%$ dipengaruhi oleh variabel lain di luar penelitian

\section{DAFTAR PUSTAKA}

Agustin, R. P. 2014. Hubungan antara produktivitas kerja terhadap pengembangan karir pada karyawan PT Bank Mandiri Tarakan. E-Journal Psikologi, 02(01), $24-40$.

Ardana, I Komang dkk. 2012. Manajemen Sumber Daya Manusia. Yogyakarta : Graha ilmu.

Badriyah, Mila. 2017. Manajemen Sumber Daya Manusia,Cetakan Keuda. Bandung : Pustaka Setia.

Bangun, Wilson. 2012. Manajemen Sumber Daya Manusia. Jakarta : Erlangga.

Fahmi, Irham. 2016. Manajemen Sumber Daya Manusia-Teori dan Aplikasi. Bandung: Alfabeta.

Hasibuan, Malayu S.P. 2016. Manajemen Sumber Daya Manusia. Edisi Revisi. Jakarta : Penerbit PT Bumi Aksara

Handoko, T. Hani. 2011. Manajemen Personalia dan Sumberdaya Manusia, Edisi Kedua. Yogyakarta: Penerbit BPFE.

Kadarisman, 2012, Manajemen Pengembangan Sumber Daya Manusia. Jakarta : Rajawali Pers.

Maurits L S K. 2011. Selintas Tentang Kelelahan Kerja. Yogyakarta : Amara Books. 


\section{당 \\ Jurnal Ilmiah METADATA}

Sinungan,Muchdarsyah. 2014. Produktivitas : Apa dan Bagaimana. Jakarta: PT. Bumi Aksara.

Sulaeman, Ardika. 2014. Pengaruh Upah dan Pengalaman Kerja terhadap Produktivitas Karyawan Kerajinan Ukiran Kabupaten Subang. Jurnal Trikonomika Vol. 13, No. 1, Juni 2014. ISSN 2355-7737.

Sugiyono. 2015. Metode Penelitian Kombinasi (Mix Methods). Bandung : Alfabeta

Sutrisno, Edy. 2013. Manajemen Sumber Daya Manusi, Edisi Pertama. Jakarta : Kencana.

Riani, Asri Laksmi. 2011. Budaya Organisasi, Edisi Pertama, Cetakan Pertama. Yogyakarta: Graha Ilmu.

Karim, A. (2019). HUBUNGAN DISIPLIN KERJA DAN SIKAP INOVATIF DENGAN KINERJA GURU SMA NEGERI 14 MEDAN. Jurnal Ilmiah METADATA, 1(2), 1-16.

Sitompul, S. (2019). PENGARUH MOTIVASI DAN KEPEMIMPINAN TERHADAP PRESTASI KERJA PADA PT. PLN (PERSERO)UNITINDUK PEMBANGUNAN II MEDAN. Jurnal Ilmiah METADATA, 1(2), 93-105.

Nasution, L. (2019). PENGARUH KESELAMATAN KERJA TERHADAP KINERJA KARYAWAN PADA PT. PLN (Persero) UNIT INDUK PEMBANGUNAN II MEDAN. Jurnal Ilmiah METADATA, 1(2), 62-72.

Ichsan, R. (2020). PENGARUH PELATIHAN TERHADAP PRESTASI KERJA KARYAWAN PADA PDAM TIRTANADI CABANG PADANG BULAN MEDAN. Jurnal Ilmiah METADATA, 2(1), 71-77. 